\title{
Expression of Prostaglandins-Related Genes in Erythrocytes of Chickens Infected with H9N2 Subtype of Avian Influenza Virus
}

\author{
Muhammad Farhan Qadir ${ }^{1}$, Xin-Yu Han ${ }^{1}$, Meng-li Qiao', Ying Wang ${ }^{1}$, Ding Zhang ${ }^{1}$, \\ Yu-hai Bi ${ }^{1,2}$, Ali Raza Jahejo ${ }^{1}$,Qian-qian Cheng ${ }^{1}$ and Wen-xia Tian ${ }^{1, *}$ \\ ${ }^{1}$ College of Veterinary Medicine, Shanxi Agricultural University, Jinzhong, 030801, \\ China \\ ${ }^{2}$ CAS Key Laboratory of Pathogenic Microbiology and Immunology, Collaborative \\ Innovation Center for Diagnosis and Treatment of Infectious Disease, Institute \\ of Microbiology, Center for Influenza Research and Early-Warning (CASCIRE), \\ Chinese Academy of Sciences, Beijing 100101, China
}

\begin{abstract}
A B S T R A C T
Chicken's erythrocytes are most abundant cells circulating in the body which participate in inflammation and immune responses. However, expression levels of prostaglandins-related genes in H9N2 infected chicken's erythrocytes have not been studied yet. So, the present study was designed to investigate the PG-related genes in erythrocytes of H9N2 infected chickens. In current study, qRT-PCR and Western blot analysis were performed to identify the expression levels of PG-related genes (COX-2, GSTA3, PTGDS, PTGES, PTGER3 and PTGER4) in erythrocytes of H9N2 infected chickens at time intervals of $0,2,6$ and $10 \mathrm{~h}$ and $P<0.05$ was considered as statistically significant. Expression levels were increased significantly in case of COX-2 at 0 and $6 \mathrm{~h}$, GSTA 3 and PTGDS at $0 \mathrm{~h}$ and PTGER 4 at $2 \mathrm{~h}$ of infection, while decreased expression was observed in case of COX-2 at $2 \mathrm{~h}$, GSTA3 at $10 \mathrm{~h}$, PTGDS at 6 and 10 $\mathrm{h}$, PTGES at 2 and $10 \mathrm{~h}$, PTGER 3 at $0,2,6$ and $10 \mathrm{~h}$ and PTGER4 at 6 and $10 \mathrm{~h}$ of infection. Besides, western blot analysis of COX-2 protein expression further supported the mRNA results. Moreover, this was first study indicating the expression levels of PG-related genes in the H9N2 infected chicken's erythrocytes. This study may provide a new biomarker to detect H9N2 in chickens. Future studies are in process to know the morphological features, and to evaluate the mechanism exhibited by erythrocytes in response to H9N2 with new experimental evidence in chickens.
\end{abstract}

\begin{tabular}{l} 
Article Information \\
Received 07 July 2020 \\
Revised 25 August 2020 \\
Accepted 03 September 2020 \\
Available online 27 May 2021 \\
Authors' Contribution \\
\hline MFQ and WXT conceived and \\
designed the experiments. XYH, \\
MLQ and QQC analyzed the data. \\
MFQ, ARJ and YW performed the \\
experiments. DZ and YHB suggested \\
analyses. MFQ wrote the paper. WXT \\
helped in revision of manuscript. All \\
authors read and approved the final \\
draft of the manuscript. \\
Key words \\
\hline Avian influenza, Chickens, \\
Erythrocytes, H9N2, Prostaglandins.
\end{tabular}

\section{INTRODUCTION}

A vian influenza (AI) is known as economically important viral disease of poultry industry worldwide. It is negative sense RNA virus with 80 to 120 $\mathrm{nm}$ of diameter and belongs to orthomyxoviridae family. AI virus is classified into five genera named as Isavirus, Thogoto virus and three types of influenza A, B and C. Among these five genera, type-A influenza viruses are of vital importance, effecting many avian species. AI can be distinguished in two types based on its pathogenicity known as highly pathogenic avian influenza (HPAI) virus and low pathogenic avian influenza (LPAI) virus. Currently, 9 neuraminidase (NA) and 16 different hemagglutinin (HA) from H1 to H16 are serological subtypes of type-A influenza circulating in birds (Fouchier et al., 2005; Palese and Shaw, 2007).

\footnotetext{
* Corresponding author: wenxiatian@126.com 0030-9923/2021/0004-1417 \$ 9.00/0

Copyright 2021 Zoological Society of Pakistan
}

Among all influenza viruses, H9N2 avian influenza virus (AIV) is known as LPAIV and mainly infects poultry populations, human and pigs (Nagy et al., 2017; Xing et al., 2008). During infection, chickens are often free of clinical signs, but infection can increase the severity in association with other respiratory pathogens (co-infection) (Hassan et al., 2017; Xing et al., 2009). H9N2 AIV was isolated in America in 1966, after that virus has been detected in many countries. H9N2 has been reported in turkeys, chickens, pheasants, and domestic ducks throughout Asia, Africa, the Middle East and Europe from1995 to 1997. H9N2 AI virus was isolated from infected chickens in Guangdong province in 1994, known as first reported case of H9N2 in China. Moreover, it is known as low pathogenic AI virus, because it leads to high morbidity and low mortality. Most important, it was stated that H9N2 have the ability to cross the species boundaries to infect humans in Hong Kong and Guangzhou, China (Lv et al., 2015). LPAIV have also been known to donate internal genes to the highly pathogenic AIV (HPAIV) H5N1 in humans in Hong Kong. H9N2 viruses have under-gone extensive re-assortment 
with many subtypes of AI viruses, including HPAIV (H5N1, and H7N3) viruses. Moreover, H9N2 virus has a significant zoonotic threat, so poultry vaccination of entire poultry birds against H9N2 virus is a possible way to decrease infection and transmission among birds (Guan et al., 1999; Iqbal et al., 2013). However, H9N2 virus can spread by fecal-oral route and, has the ability to replicate in avian guts. Moreover, H9N2 virus can spread with migration of birds, due to which it is very difficult to prevent and control. Previous literature indicates that AI viruses can lead to severe epithelial apoptosis by invading in intestinal cells, (HT-29 and Caco-2 cells) (Jahangir et al., 2010; Qu et al., 2012).

Prostaglandins (PGs) are actually present in almost all tissues in the body, and are known as physiologically active lipid compounds. PGs play a vital role in autocrine and paracrine cellular interactions in animals. It was stated that PGs are involved in activation and inhibition of immune responses. Previous studies stated that inducible COX isozyme is involved to cause several diseases, that's why, researchers were interested and involved in the cyclooxygenase (COX)-2-dependent biological responses (Nørregaard et al., 2015). PGs synthesis was initiated by arachidonic acid via conversion of COX (1-2) to PGH2, followed by response of many PG synthases, PGH2 was transformed into prostanoid (more stable) end products (Niu et al., 2019). PGs are considered as the basic products of COX-2, followed by autocrine and paracrine modes leads to activation of various intracellular pathways and induced antiapoptotic activity cellular proliferation and angiogenesis ( $\mathrm{He}$ et al., 2016). It was stated that isomerization of PGH2 to PGE2 was catalysed by prostaglandin E synthase (PTGES). Previous reports revealed that PTGES activity was seen in cytosolic and membrane-linked fractions of several cells and tissues, and COX-2-dependent PGE2 generation promoted PTGES activity. PGE2 exerted its actions by acting on four G-protein coupled receptors, PTGER-1, 2, 3 and 4 that were implicated in signal transduction, tissue localization, and regulation of expression. Among these, PTGER4 had vital role in both PGE2-stimulated bone formation and resorption by activating the synthesis of cAMP, whereas PTGER3 was coupled to $\mathrm{G} \alpha \mathrm{i}$ and inhibited cAMP synthesis. Prostaglandin D2 synthase (PTGDS) effects the formation of prostaglandin D2 (PGD2) by catalysing the isomerization of $\mathrm{PGH} 2$, which has been implicated in the regulation of diverse biological processes, including vasodilatation, inhibition of platelet aggregation, inflammation, immunomodulation and apoptosis (Blackwell et al., 2010; Niu et al., 2019).

Previously, identification of PG-related genes were done in chicken's Tibial dyschondroplasia (Tian et al., 2013). Till date, there was no study reporting the PGrelated genes expression in H9N2 infected chicken's erythrocytes, so based on the significance of H9N2 in chickens, this was the first attempt to evaluate the effect of PG-related genes expression changes on the erythrocytes of chickens infected with H9N2. qRT-PCR for mRNA expression and western blot for protein expression was performed to observe the expression levels of PG-related genes.

\section{MATERIALS AND METHODS}

\section{Experimental design}

Specific-pathogen-free (SPF) chickens purchased from Longkol Company (Taigu, Shanxi). Fresh blood was taken from the wing vein of SPF chickens and erythrocytes $\left(2 \times 10^{8}\right)$ were taken in a $2 \mathrm{~mL}$ centrifuge tube already containing a sufficient amount of cell maintenance solution. It was divided into two equal groups i.e. an experimental group and control group. The experiment was carried out in an Animal Biosafety Level-2 Laboratory. After isolation of erythrocytes (by following the procedure describe below), $50 \mu \mathrm{L}$ of erythrocytes were taken into 16 different centrifuge tubes containing Dulbecco's Modified Eagle Medium (DMEM) maintenance solution (Solarbio, Beijing, China). These 16 tubes were segregated into four main groups $(0,2,6$ and $10 \mathrm{~h})$ containing 4 each. In each group, four tubes were divided into control and experimental sub-groups (each sub-group containing 2 tubes) followed by H9N2 virus treatment in experimental groups as describe below.

\section{Erythrocyte isolation}

Fresh blood $4 \mathrm{~mL}$ was taken from SPF chickens, and 2:1:1 (8mL: $4 \mathrm{~mL}: 4 \mathrm{~mL})$ ratio of lymphocyte separation solution, PBS and blood were taken respectively. Initially, PBS was mixed to blood. Secondly, lymphocyte separation solution (superficial or upper layer) was added slowly to avoid the mixing, followed by centrifugation at $2000 \mathrm{r} /$ min for $20 \mathrm{~min}$. Supernatant was removed and infranatant (lying below a sediment) having pure erythrocytes was collected and separated. Then, it was re-suspended in PBS, centrifuged at $2000 \mathrm{r} / \mathrm{min}$ followed by 3 washings for 10 min each. Pure erythrocytes were obtained by a procedure as described by Niu et al. (2018).

\section{Virus treatment}

AIV subtype H9N2 obtained from Shenzhen, China. H9N2 virus solution $(100 \mu \mathrm{L})$ was added into experimental sub-groups of all 4 main groups followed by addition of 
$900 \mu \mathrm{L}$ of DMEM to make the final volume $1050 \mu \mathrm{L}$. While, rest of sub-groups without H9N2 treatment were considered as control groups. After completion of incubation with the virus, erythrocytes were isolated at $0,2,6$ and $10 \mathrm{~h}$ by centrifugation at $2000 \mathrm{r} / \mathrm{min}$ for 20 min. The supernatant was taken into Eppendorf tubes and stored separately. Erythrocytes were washed 3-times with PBS and stored for further experiments.

\section{$R N A$ extraction, $c D N A$ synthesis and $q R T-P C R$}

RNA extraction, cDNA synthesis and thermal cycling parameters were done by following the methods previously described by Wang et al. (2018). Briefly, the total mRNAs were extracted from H9N2 infected erythrocytes and isolated by RNAiso Plus (Takara Bio Inc., Dalian, China) by following the instructions of the manufacturer. qRTPCR was done to explore the expression level of PG related genes in erythrocytes of chicken at $0,2,6$ and $10 \mathrm{~h}$ of infection. Primers for PG related genes (Table I) were selected and designed by primer express 3.0 software which was synthesized by Genery Biotechnology (Shanghai, China). 18SrRNA was taken as house-keeping gene. Real-time PCR was performed with TaKaRa SYBR Premix Ex Taq ${ }^{\mathrm{TM}}$ II (Takara Bio Inc., Dalian, China) using a 1:10 dilution of cDNA, 1.5pmol of primers and $10 \mu \mathrm{L}$ final volume and qRT-PCR was performed by the QuantStudio $^{\text {TM }} 6$ (Applied Biosystems, USA).

\section{Western blot analysis}

Western blotting was performed for COX-2 to confirm the results of qRT-PCR. Protein concentration was determined by BCA protein assay kit (Beyotime Institute of Biotechnology, Ltd.) by using Bovine albumin serum as standard. Then, the purified protein of $30 \mu \mathrm{L}$ was added in EP and $4 \times$ sample buffer solution $(10 \mu \mathrm{L})$ was mixed and placed at $100^{\circ} \mathrm{C}$ water bath for $5 \mathrm{~min}$ heat to denature the protein. Denatured Protein was loaded and resolved by electrophoresis on $8 \%$ Sodium Dodecyl sulfatepolyacrylamide gel (SDS-PAGE) then, the required stripe was transferred on to a nitrocellulose (NC) membrane and run for $60 \mathrm{~min}$ at $35 \mathrm{~V}$. Blots were blocked with 5\% dried milk (without fat) for $2 \mathrm{~h}$ at room temperature followed by incubation with $\beta$-actin (1:1000 dilution, Santa Cruz Biotechnology, Inc., USA) and COX-2 (1:1000 dilution, Santa Cruz Biotechnology, Inc., USA) primary antibodies; overnight at $4^{\circ} \mathrm{C}$. Later, the membranes were incubated with HRP-conjugated goat anti-rabbit secondary antibody (1:3000) for $2 \mathrm{~h}$ at room temperature followed by PBST multiple washing, and protein bands were visualized by enhanced chemi-luminescence (Super ECL, KeyGEN BioTECH). Alpha View (version 3.2.2.0) software was used for optical density calculation. $\beta$-actin was set as an internal control.

\section{Statistical analysis}

The qRT-PCR data was analysed by using the $2^{-\Delta \Delta C t}$ method. Experimental data was shown as mean \pm SEM (standard error of means). Statistical analyses were performed using GraphPad Prism 5 software (GraphPad software Inc., San Diego, USA). Differences between control and experimental groups were calculated by using two-way analysis of variance (ANOVA) followed by Tukey's Multiple Comparison test. The value of $P<0.05$ was regarded statistically significant.

Table I.- PG-related genes and primer sequences used for qRT-PCR.

\begin{tabular}{llcc}
\hline Genes & Primer sequence $\left(\mathbf{5}^{\prime} \rightarrow \mathbf{3}^{\prime}\right)$ & GenBank accession No. & Annealing temp. \\
\hline COX-2 & $\begin{array}{l}\text { Forward-CCGTTCCTCTACAACAACTCCA } \\
\text { Reverse- TTCCCACCAGAACCCTA }\end{array}$ & NM_001167719 & $55^{\circ} \mathrm{C}$ \\
GSTA3 & $\begin{array}{l}\text { Forward- TACATCGCAGGGAAATACA } \\
\text { Reverse- GGAGAGAAAGGAAACACCA }\end{array}$ & NM_001001777 & $55^{\circ} \mathrm{C}$ \\
& Forward- GCACCTGCTGAAGATGTGTA & NM_204259.1 & $55^{\circ} \mathrm{C}$ \\
PTGDS & Reverse- CCTCTTCTCGCACTGTTCAC & & $55^{\circ} \mathrm{C}$ \\
& Forward- TTCGCCTTCTACAGCACGAT & XM_015279472 & $55^{\circ} \mathrm{C}$ \\
PTGER3 & Reverse- TTCTTCCTGAGCCTCACTTGT & NM_001040468 & $55^{\circ} \mathrm{C}$ \\
PTGER4 & Forward- TCTCGGCAGAAACCCAAAGC & & \\
& Reverse- CGGAGCAGCAGATAAACCCAC & NM_001081503 & $55^{\circ} \mathrm{C}$ \\
18 FrRNA & Forward- TCAGGAAAGCCATCGAGAAG & & FM165414 \\
\hline
\end{tabular}




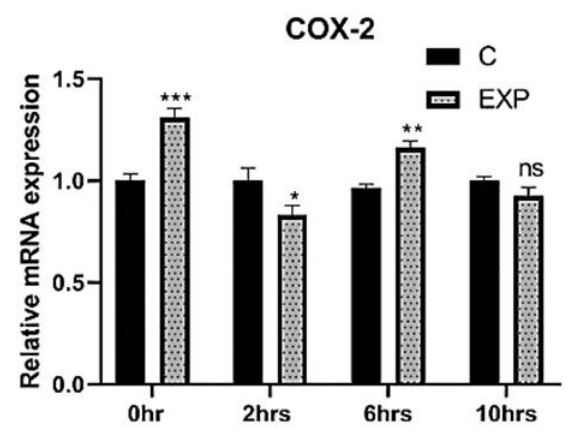

GSTA3

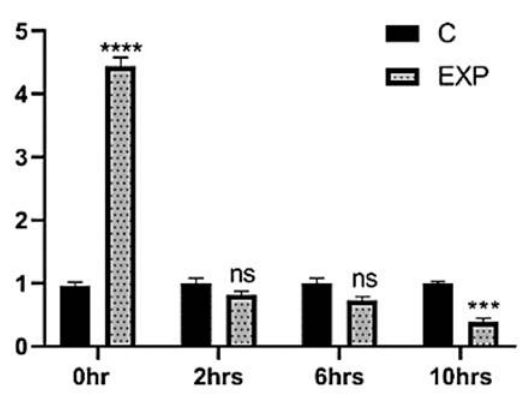

PTGER3

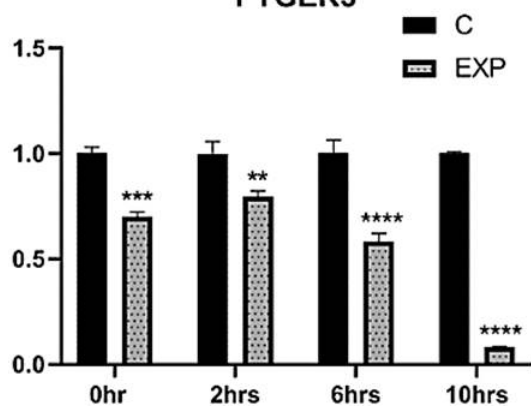

PTGDS

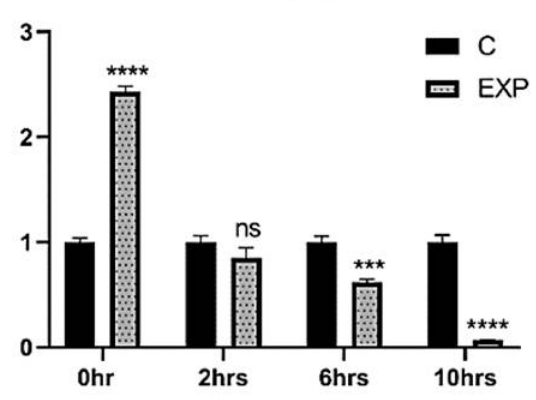

PTGER4

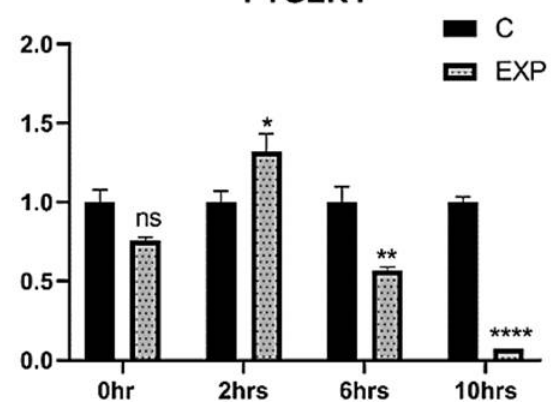

Fig. 1. mRNA expression of PG-related genes in the erythrocytes of chickens at time intervals of $0,2,6$ and $10 \mathrm{~h}$. Asterisks $(*)$ indicating significant differences among experimental and control groups $\left({ }^{*} P<0.05 ; * * p<0.01 ; * * * P<0.0004 ; * * * * P<\right.$ 0.0001; ns, not significant); C, control; Exp, experimental.

\section{RESULTS}

$m R N A$ expression level of $P G$ related genes in chicken erythrocytes

Expression levels of PG-related genes including COX-2, GSTA3, PTGDS, PTGES, PTGER3 and PTGER4 were analysed and presented in Figure 1. mRNA expression of COX-2 was significantly increased $(P<0.05)$ at 0 $(1.312 \pm 0.041)$ and $6(1.164 \pm 0.032) \mathrm{h}$ while significant decreased $(P<0.05)$ at $2(0.830 \pm 0.046) \mathrm{h}$ of infection. At $0 \mathrm{~h}$ GSTA3 $(4.435 \pm 0.143)$ and PTGDS (2.432 \pm 0.050$)$ were increased significantly $(P<0.05)$, while GSTA3 at $10 \mathrm{~h}(0.390 \pm 0.051)$ and PTGDS at $6(0.618 \pm 0.028)$ and $10 \mathrm{~h}(0.070 \pm 0.001)$ were significantly decreased $(P<$ 0.05). However no significance was observed in COX-2 at $10 \mathrm{~h}(0.926 \pm 0.040)$, GSTA3 at $2(0.815 \pm 0.058)$ and $6 \mathrm{~h}(0.733 \pm 0.053)$ and PTGDS at $2 \mathrm{~h}(0.850 \pm 0.097)$. Expression levels of PTGES was decreased significantly $(P<0.05)$ at $2(0.711 \pm 0.050)$ and $10 \mathrm{~h}(0.170 \pm 0.047)$, and PTGER3 at $0(0.700 \pm 0.022), 2(0.794 .00 \pm 0.027)$, $6(0.582 \pm 0.039)$ and $10 \mathrm{~h}(0.082 \pm 0.0004)$ while no significance was observed in PTGES at $0(1.080 \pm 0.054)$ and $6 \mathrm{~h}(0.983 \pm 0.029)$. Moreover, PTGER4 expression level was increased significantly $(P<0.05)$ at $2 \mathrm{~h}(1.322$ $\pm 0.110)$ while decreased significantly $(P<0.05)$ at 6
$(0.566 \pm 0.023)$ and $10 \mathrm{~h}(0.074 \pm 0.0003)$. However, no significant changes were observed at $0 \mathrm{~h}(0.757 \pm 0.019)$.

\section{Protein expression of $\mathrm{COX}-2$}

Western blot was performed to evaluate the protein expression level of COX-2. At all-time intervals of $(0,2$, 6 and $10 \mathrm{~h}$ ) in comparison with their respective control groups, protein expression level of COX-2 was increased significantly at $0 \mathrm{~h}(1.313 \pm 0.035)$ while decreased at $2 \mathrm{~h}$ $(0.773 \pm 0.049)$ of infection. However, no significance was observed at $6(1.056 \pm 0.023)$ and $10 \mathrm{~h}(0.953 \pm 0.029)$ of infection (Fig. 2). Protein expression level of COX-2 was consistent with the mRNA expression level of COX2 , indicating that protein expression of all other genes will also support mRNA expression of their respective genes as compared to their control groups.

\section{DISCUSSION}

The role of viral proteins in the induction and regulation of apoptosis have been studied (Ito et al., 2002), but relatively less information was available about PG-related genes expression in the erythrocytes of H9N2 infected chickens. So, in current study, mRNA expression pattern of PG-related genes including COX-2, GSTA3, 
PTGDS, PTGES, PTGER3 and PTGER4 were determined and evaluated in H9N2 infected chicken's erythrocytes. Hence, qRT-PCR results revealed that PG-related genes were expressed in chicken erythrocytes, in which COX2 altered expression was observed. COX-2 is known as inflammatory factor and involved in several inflammatory diseases. Its increased expression have shown that COX2 is also involved in regulating the chronic pulmonary inflammation (Yuan et al., 2018). Hence H9N2 infected chicken's erythrocytes also induces the expression of COX-2 which may lead to inflammation in different organs of chickens. Uribe et al. (2018) also investigated the increased COX-2 expression in the mouse colonic mucosa which supports the current COX-2 findings. In previous studies Shahnazi et al. (2015) stated that an increased COX-2 expression is also associated with intra-follicular PGE2 levels in human females. COX-2, is involved in metabolic conversion of arachidonic acid to PGs and its expression may enhance in osteoblasts and stromal cells (Ohshiba et al., 2003; Wang et al., 2014).

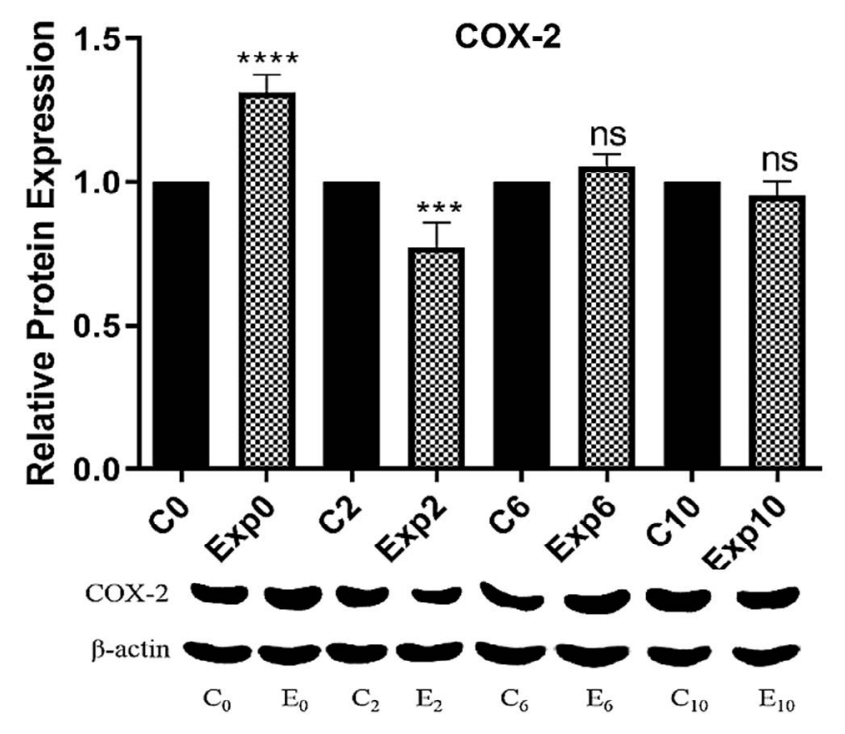

Fig. 2. Protein expression of COX-2 in the erythrocytes of chickens at time intervals of $0,2,6$ and $10 \mathrm{~h}$ (protein bands derived from Western blot). Data represent mean \pm SEM. Asterisks (*) indicating significant differences compared to control groups $(* P<0.05 ; * * P<0.01 ; * * * P<0.0004$; $* * * * P<0.0001$; ns, not significant); C, control; Exp, experimental.

GSTA3 expression level was markedly increased (upregulated) at early hour $(0 \mathrm{~h})$ indicating very high severity in early stage of H9N2 infection. However, expression level was significantly decreased (down-regulated) at 10 $\mathrm{h}$ of infection, indicate that birds may become immune to infection so severity of infection decreases. Xiao etal.(2016) investigated both over-expression and down expression of GSTA3 in renal tubular epithelial-mesenchymal transition and renal cortex in rats respectively, which was in favour of current mRNA expression results of GSTA3. It is known as catalytically important enzyme in humans and involved in the production of different types of hormones i.e. steroid hormones (Yi et al., 2018). Increased expression of GSTA3 at early stage may be considered as a part of response of host to virus indicating that, this gene is involved in H9N2 infection in the erythrocytes of chickens at different stages of time period.

Expression levels of PTGDS was up-regulated at 0 $\mathrm{h}$ of infection leading to down-regulation at 6 and $10 \mathrm{~h}$ of infection indicating the immune status and infection severity time to time at different stages of incubation. Down regulation at 6 and $10 \mathrm{~h}$ of infection may be due to the auto-activation of immune mechanism, leading to recovery of birds infected with H9N2 subtype of AI virus infection. PTGDS involved in PGD2 production in peripheral tissues leading to regulation of inflammation, apoptosis and immunomodulation (Ragolia et al., 2001; Niu et al., 2019). Current results suggest that expression changes of PTGDS is mediated by PGD2 production in response to H9N2 infection leading to apoptosis and inflammation in different body parts of chickens.

In case of PTGES, mRNA expression was significantly deceased at later stage of infection, indicating less severity of H9N2 infection in chickens. This less severity could be due to the increased immunity level with the passage of time of infection, as birds may gain some immunity themselves against the specific pathogen or infection in later hours of infection. Moreover, expression of PTGES is involved in the synthesis of PGE2 that is known as inflammatory mediator (Niu et al., 2019). It is also involved in induction of bone resorption so, the altered expression levels and other related mediators due to PTGES, indicate the presence of H9N2 virus in the infected erythrocytes. In another study, expression of PTGES was evaluated downregulated in peripheral blood mononuclear cells in cattle which was similar to the current mRNA results of PTGES (Yang et al., 2016).

PTGER3 and PTGER4, both are known as G-protein members and have influence on the inflammatory mediator PGE2 (Sugimoto and Narumiya, 2007; Niu at al., 2019). PTGER3 was significant down-regulated at all-time periods, while highly down-regulated in later stages ( 6 and $10 \mathrm{~h}$ ) of infection, indicating that birds may become immune to infection so expression of PTGER3 was supressed by H9N2 AI virus in all-time periods of infection. While, PTGER4 expression level was significantly up-regulated at $2 \mathrm{~h}$ showing that $\mathrm{H} 9 \mathrm{~N} 2$ infection was more severe as compared to other time periods (down-regulated). Current 
PTGER3 and PTGER4 expression levels were similar to the expression levels observed in fetal tissues as compared to maternal tissues in human (Grigsby et al., 2006). All the results revealed that erythrocytes have the tendency to respond the viral infections as H9N2 AIV.

Meanwhile, western blotting was done to explore the protein expression levels of COX-2 at same time intervals of $0,2,6$ and $10 \mathrm{~h}$ of H9N2 infection and, in comparison with their respective control groups, protein expression of COX-2 was significantly increased, and significance was increased with the passage of time of infection. Protein expression of COX-2 supported the mRNA results of COX2 , which indicates that if protein expression of COX-2 was similar to its mRNA expression levels, so it can be said that protein expression of rest of genes should be similar to the their respective mRNA expression levels. Previously, another researcher also investigated the COX-2 protein expression in the spleen of sheep, which was similar to the current COX-2 protein expression (Yang et al., 2018). In another study, Streicher et al. (2010) investigated the COX2 over-expression induced by cardio-myocyte leading to the cardiac hypertrophy in mice. The COX enzyme system is known as major pathway that is involved in conversion of arachidonic acid to PGs. COX-2 is considered as inducible form of COX enzyme system leading to PGs synthesis by arachidonic acid. COX-2 is the first and foremost enzyme mainly expressed by inflammatory cells, i.e. macrophages, and can be induced by TNF and EFG. Hence, in current study COX-2 was selected for its protein expression analysis through western blotting.

\section{CONCLUSION}

In conclusion, six PG-related genes (COX-2, GSTA3, PTGDS, PTGES, PTGER3 and PTGER4) were well expressed and observed in chicken's erythrocytes indicating the severity of $\mathrm{H} 9 \mathrm{~N} 2$ infection at different time periods of incubation. Generally, H9N2 promoted the expression of several genes at initial hours of infection and supressed at later time periods (h) of infection in all types of genes. Further confirmation was done by evaluating protein expression bands of COX-2 by western blotting. Protein expression level of COX-2 was almost similar to its mRNA expression. This was the first study reporting alterations in expression levels of PG-related genes in H9N2 infected chicken erythrocytes. Current findings have provided a new perspective to find a therapeutic intervention by targeting PG-related genes for H9N2 infected chicken erythrocytes. Further studies are required to know more host factors that may control the expression level of genes during infection or treat from H9N2 infection in chickens.

\section{ACKNOWLEDGEMENT}

This work was supported by the National Key R\&D Program (2016YFD0500800, 2016YFD0500806), the China-U.S. Collaborative Program on Emerging and Re-emerging Infectious Diseases, "131" Leading Talent Project for Colleges and Universities of Shanxi Province, Scientific and Technological Innovation Team for Disease Control and Prevention in Shanxi Agricultural University.

\section{Ethical approval}

The management of the experimental animals was in agreement with the welfare guidelines approved by the College of Animal Science and Veterinary Medicine of Shanxi Agricultural University, China (Number 88, 2010).

Statement of conflict of interest

The authors have declared no conflict of interests.

\section{REFERENCES}

Blackwell, K.A., Raisz, L.G. and Pilbeam, C.C., 2010. Prostaglandins in bone: Bad cop, good cop? Trends Endocrinol. Metab., 21: 294-301. https://doi. org/10.1016/j.tem.2009.12.004

Eilati, E., Pan, L., Bahr, J.M. and Hales, D.B., 2012. Age dependent increase in prostaglandin pathway coincides with onset of ovarian cancer in laying hens. Prostaglandins, Leukot Essent. Fatty Acids, 87: 177-184. https://doi.org/10.1016/j. plefa.2012.09.003

Fouchier, R.A., Munster, V., Wallensten, A., Bestebroer, T.M., Herfst, S., Smith, D., Rimmelzwaan, G.F., Olsen, B. and Osterhaus, A.D., 2005. Characterization of a novel influenza $A$ virus hemagglutinin subtype (H16) obtained from blackheaded gulls. J. Virol., 79: 2814-2822. https://doi. org/10.1128/JVI.79.5.2814-2822.2005

Grigsby, P.L., Sooranna, S.R., Adu-Amankwa, B., Pitzer, B., Brockman, D.E., Johnson, M.R. and Myatt, L., 2006. Regional expression of prostaglandin E2 and F2 alpha receptors in human myometrium, amnion, and choriodecidua with advancing gestation and labor. Biol. Reprod., 75: 297-305. https://doi. org/10.1095/biolreprod.106.051987

Guan, Y., Shortridge, K.F., Krauss, S. and Webster, R.G., 1999. Molecular characterization of H9N2 influenza viruses: were they the donors of the "internal" genes of H5N1 viruses in Hong Kong? Proc. natl. Acad. Sci., 96: 9363-9367. https://doi. org/10.1073/pnas.96.16.9363

Hassan, K.E., Ali, A., Shany, S.A. and El-Kady, M.F., 
2017. Experimental co-infection of infectious bronchitis and low pathogenic avian influenza H9N2 viruses in commercial broiler chickens. Res. Vet. Sci., 115: 356-362. https://doi.org/10.1016/j. rvsc. 2017.06 .024

He, A., Ji, R., Shao, J., He, C., Jin, M. and Xu, Y., 2016. TLR4-MyD88-TRAF6-TAK1 complexmediated NF- $\kappa \mathrm{B}$ activation contribute to the antiinflammatory effect of V8 in LPS-induced human cervical cancer SiHa cells. Inflammation, 39: 172181. https://doi.org/10.1007/s10753-015-0236-8

Iqbal, M., Yaqub, T., Mukhtar, N., Shabbir, M.Z. and McCauley, J.W., 2013. Infectivity and transmissibility of H9N2 avian influenza virus in chickens and wild terrestrial birds. Vet. Res., 44: 100. https://doi.org/10.1186/1297-9716-44-100

Ito, T., Kobayashi, Y., Morita, T., Horimoto, T. and Kawaoka, Y., 2002. Virulent influenza A viruses induce apoptosis in chickens. Virus Res., 84: 27-35. https://doi.org/10.1016/S0168-1702(01)00414-2

Jahangir, A., Ruenphet, S., Hara, K., Shoham, D., Sultana, N., Okamura, M. and Takehara, K., 2010. Evaluation of human intestinal epithelial differentiated cells (Caco-2) for replication, plaque formation and isolation of avian influenza viruses. J. Virol. Meth., 169: 232-238. https://doi. org/10.1016/j.jviromet.2010.07.023

Lv, J., Wei, L., Yang, Y., Wang, B., Liang, W., Gao, Y., Xia, X., Gao, L., Cai, Y. and Hou, P., 2015. Amino acid substitutions in the neuraminidase protein of an H9N2 avian influenza virus affect its airborne transmission in chickens. Vet. Res., 46: 44. https:// doi.org/10.1186/s13567-014-0142-3

Nagy, A., Mettenleiter, T. and Abdelwhab, E., 2017. A brief summary of the epidemiology and genetic relatedness of avian influenza H9N2 virus in birds and mammals in the Middle East and North Africa. Epidemiol. Infect., 145: 3320-3333. https://doi. org/10.1017/S0950268817002576

Niu, S., Jahejo, A.R., Jia, F.J., Li, X., Ning, G.B., Zhang, D., Ma, H.I., Hao, W.F., Gao, W.W. and Zhao, T.J., 2018. Transcripts of antibacterial peptides in chicken erythrocytes infected with Marek's disease virus. BMC Vet. Res., 14: 363. https://doi. org/10.1186/s12917-018-1678-7

Niu, S., Wang, C.X., Jia, F.J., Jahejo, A.R., Li, X., Ning, G.B., Zhang, D., Ma, H.L., Hao, W.F., Gao, W.W., Zhao, Y.J., Gao, S.M., Li, J.H., Li, G.L., Yan, F., Gao, R.K., Huo, N.R., Tian, W.X. and Chen, H.C., 2019. The expression of prostaglandinsrelated genes in erythrocytes of broiler chicken responds to thiram-induced tibial dyschondroplasia and recombinant glutathione-S-transferase A3 protein. Res. Vet. Sci., 124: 112-117. https://doi. org/10.1016/j.rvsc.2019.03.004

Nørregaard, R., Kwon, T.H. and Frøkiær, J., 2015. Physiology and pathophysiology of cyclooxygenase-2 and prostaglandin E2 in the kidney. Kidney Res. Clin. Pract., 34: 194-200. https://doi.org/10.1016/j.krcp.2015.10.004

Ohshiba, T., Miyaura, C. and Ito, A., 2003. Role of prostaglandin $\mathrm{E}$ produced by osteoblasts in osteolysis due to bone metastasis. Biochem. biophys. Res. Commun., 300: 957-964. https://doi. org/10.1016/S0006-291X(02)02937-6

Palese, P. and Shaw, M.L., 2007. Orthomyxo-viridae: The viruses and their replication. In: Fields virology (eds. D.M. Knipe and P.M. Howley), $5^{\text {th }}$ ed. Lippincott Williams \& Wilkins, Philadelphia, pp. 1647-1689.

Qu, B., Li, X., Gao, W., Sun, W., Jin, Y., Cardona, C.J. and Xing, Z., 2012. Human intestinal epithelial cells are susceptible to influenza virus subtype H9N2. Virus Res., 163: 151-159. https://doi.org/10.1016/j. virusres.2011.09.007

Ragolia, L., Palaia, T., Frese, L., Fishbane, S. and Maesaka, J.K., 2001. Prostaglandin D2 synthase induces apoptosis in PC12 neuronal cells. Neuro Rep., 12: 2623-2628. https://doi. org/10.1097/00001756-200108280-00008

Shahnazi, V., Zaree, M., Nouri, M., MehrzadSadaghiani, M., Fayezi, S., Darabi, M., Khani, S. and Darabi, M., 2015. Influence of $\omega-3$ fatty acid eicosapentaenoic acid on IGF-1 and COX-2 gene expression in granulosa cells of PCOS women. Iran J. Reprod. Med., 13: 71.

Streicher, J.M., Kamei, K., Ishikawa, T.O., Herschman, H. and Wang, Y., 2010. Compensatory hypertrophy induced by ventricular cardiomyocyte-specific COX-2 expression in mice. J. mol. cell. Cardiol., 49: 88-94. https://doi.org/10.1016/j.yjmcc.2010.01.021

Sugimoto, Y. and Narumiya, S., 2007. Prostaglandin E receptors. J. biol. Chem., 282: 11613-11617. https://doi.org/10.1074/jbc.R600038200

Sims, L.D., Weaver, J. and Swayne, D.E., 2008. Epidemiology of avian influenza in agricultural and other man-made systems. In: Animal influenza (ed. D.E. Swayne). Wiley Online Library, pp. 59-86. https://doi.org/10.1002/9781118924341.ch12

Tian, W.X., Li, J.K., Qin, P.,Wang, R., Ning, G.B., Qiao, J.G., Li, H.Q., Bi, D.R., Pan, S.Y. and Guo, D.Z., 2013. Screening of differentially expressed genes in the growth plate of broiler chickens with tibial dyschondroplasia by microarray analysis. $B M C$ 
Genom., 14: 276. https://doi.org/10.1186/14712164-14-276

Uribe, G., Villéger, R., Bressollier, P., Dillard, R.N., Worthley, D.L., Wang, T.C., Powell, D.W., Urdaci, M.C. and Pinchuk, V., 2018. Lactobacillus rhamnosus GG increases COX 2 expression and PGE2 secretion in colonic myofibroblasts via a MyD88 dependent mechanism during homeostasis. Cell Microbiol., 20: e12871. https:// doi.org/10.1111/cmi.12871

Wang, C., Niu, S., Jahejo, A., Jia, F., Li, Z., Zhang, Z., Ning, G., Zhang, D., Li, H. and Ma, H., 2018. Identification of apoptosis-related genes in erythrocytes of broiler chickens and their response to thiram-induced tibial dyschondroplasia and recombinant glutathione-S-transferase A3 protein. Res. Vet. Sci., 120: 11-16. https://doi.org/10.1016/j. rvsc.2018.08.001

Wang, Z.M., Liu, J., Liu, H.B., Ye, M., Zhang, Y.F. and Yang, D.S., 2014. Abnormal COX2 protein expression may be correlated with poor prognosis in oral cancer: A meta-analysis. Biomed Res. Int., 2014: 364207.https://doi.org/10.1155/2014/364207

Xiao, Y., Liu, J., Peng, Y., Xiong, X., Huang, L., Yang, H., Zhang, J. and Tao, L., 2016. GSTA3 attenuates renal interstitial fibrosis by inhibiting TGF-beta-induced tubular epithelial-mesenchymal transition and fibronectin expression. PLoS One, 11: e0160855. https://doi.org/10.1371/journal. pone. 0160855

Xing, Z., Cardona, C.J., Adams, S., Yang, Z., Li, J., Perez, D. and Woolcock, P.R., 2009. Differential regulation of antiviral and pro-inflammatory cytokines and suppression of Fas-mediated apoptosis by NS1 of H9N2 avian influenza virus in chicken macrophages. J. gen. Virol., 90: 1109-1118. https://doi.org/10.1099/vir.0.007518-0

Xing, Z., Cardona, C.J., Li, J., Dao, N., Tran, T. and Andrada, J., 2008. Modulation of the immune responses in chickens by low-pathogenicity avian influenza virus H9N2. J. gen. Virol., 89: 12881299. https://doi.org/10.1099/vir.0.83362-0

Yang, L., Liu, Y., Lv, W., Wang, P., Wang, B., Xue, J. and Zhang, L., 2018. Expression of interferonstimulated gene $15-\mathrm{kDa}$ protein, cyclooxygenase (COX) 1, COX-2, aldoketo reductase family 1, member B1, and prostaglandin E synthase in the spleen during early pregnancy in sheep. Anim. Sci. J., 89: 1540-1548. https://doi.org/10.1111/ asj.13101

Yang, L., Yao, X., Li, S., Chen, K., Wang, Y., Chen, L. and Zhang, L., 2016. Expression of genes associated with luteolysis in peripheral blood mononuclear cells during early pregnancy in cattle. Mol. Reprod. Dev., 83: 509-515. https://doi. org/10.1002/mrd.22647

Yi, L., Mu, H., Hu, N., Sun, J., Yin, J., Dai, K., Long, D. and Ding, D., 2018. Differential expression of NPM, GSTA3, and GNMT in mouse liver following long-term in vivo irradiation by means of uranium tailings. Biosci. Rep., 38: 536. https://doi. org/10.1042/BSR20180536

Yuan, J., Liu, R., Ma, Y., Zhang, Z. and Xie, Z., 2018. Curcumin attenuates airway inflammation and airway remolding by inhibiting NF- $\kappa \mathrm{B}$ signaling and COX-2 in cigarette smoke-induced COPD mice. Inflammation, 41: 1804-1814. https://doi. org/10.1007/s10753-018-0823-6 